\title{
ARTIGO
}

\section{Trabalho e educação profissional: refletindo sobre os conceitos de técnica e tecnologia}

\author{
Work and vocational education: \\ reflecting on the concepts of technique and technology
}

\author{
Alessandra Bernardes Bender, M.Sc. \\ Mestra em Educação Profissional e Tecnológica (IFSC. Professora do \\ Instituto Federal do Paraná (IFPR).
}

\begin{abstract}
RESUMO: Este artigo aborda a relação entre a temática do trabalho e a Educação Profissional. O problema de pesquisa advém da necessidade social de se entender os trabalhos manuais como também detentores de saberes complexos. Os objetivos envolvem: (i) diferenciar o entendimento dos conceitos de técnica e tecnologia em seu uso comum e no contexto da Educação Profissional e Tecnológica; e (ii) reconhecer a importância de todos os trabalhos, inclusive os manuais. Por visar a gerar conhecimentos para que possa ocorrer a solução de problemas específicos, a natureza da presente pesquisa é aplicada. Com relação aos procedimentos técnicos, a pesquisa se configura como bibliográfica e documental, envolvendo autores e documentos que partem do pressuposto de que a Educação Profissional se identifica pela formação integral do trabalhador. Os resultados apontam para a primordialidade da formação de trabalhadores como agentes de transformação social.
\end{abstract}

Palavras-chave: formação para o trabalho, saberes, trabalhos manuais, Educação Profissional e Tecnológica.

ABSTRACT: This paper addresses the relationship between the theme of work and the Vocational Education. The research problem arises from the social need to understand manual jobs also as holders of complex knowledge. The objectives involve: (i) differentiating the understanding of the concepts of technique and technology in their common use and in the context of Vocational and Technological Education; and (ii) recognizing the importance of all professions, including manual ones. As it aims to generate knowledge in order to solve specific problems, the nature of this research is applied. With regard to the technical procedures, the research is

Laborare. Ano IV, Número 6, Jan-Jun/2021, pp. 142-151. ISSN 2595-847X. https://revistalaborare.org/ DOI: https://doi.org/10.33637/2595-847x.2021-69 
configured as bibliographic and documentary, involving authors and documents that assume that Vocational Education is identified as qualification for work. The results point to the importance of qualifying workers as agents of social transformation.

Keywords: qualification for work, knowledge, manual jobs, Vocational and Technological Education.

\section{INTRODUÇÃO}

O presente artigo parte do pressuposto de que a Educação Profissional se constitui pela formação para o trabalho, tanto em seu sentido histórico - enquanto organizador da estrutura social — quanto em seu sentido ontológico, como constituinte de nossa humanidade. Sendo assim, é um dos objetivos deste texto diferenciar o significado de técnica e de tecnologia na Educação Profissional e Tecnológica de seu entendimento popular. Para tanto, é apresentado um breve histórico da Educação Profissional e Tecnológica no Brasil. Pretende-se rebater a tendência atual conhecida como determinismo tecnológico, que concebe o desenvolvimento tecnológico como algo autônomo, um "ser" com existência própria que pode dominar o homem. Esta concepção desqualifica os trabalhadores, desconsiderando o seu importante papel como produtores de sua existência.

O conceito de técnica enquanto intervenção qualificada no mundo para a produção da existência perpassa as abordagens referentes à Educação Profissional e Tecnológica. Engels ([1876] 1999) explica que foi por meio da transformação da natureza que o homem passou a se diferenciar dos outros animais: ao trabalhar manualmente, o homem aumenta seu conhecimento sobre as propriedades da natureza e amplia os seus horizontes. Entretanto, de acordo com Barato (2015, p. 14), ainda existe em nossa cultura a percepção de que "os conteúdos da técnica são neutros, desprovidos de significação, vazios." Persiste a noção errônea de que os trabalhadores manuais apenas realizam 'meras atividades mecânicas'. Autores como Barato entendem que a técnica não deve ser compreendida como algo externo ao homem, mas como uma propriedade sua, aquilo que o constitui como homem. E para a compreensão de tal propriedade, temos a tecnologia, que incorpora vários outros saberes além do conhecimento científico.

Além do mencionado objetivo de abordar o significado dos conceitos de técnica e tecnologia dentro do contexto da Educação Profissional e Tecnológica, também se

Laborare. Ano IV, Número 6, Jan-Jun/2021, pp. 142-151. ISSN 2595-847X. https://revistalaborare.org/ DOI: https://doi.org/10.33637/2595-847x.2021-69 
pretende reconhecer a importância de todos os trabalhos, inclusive os manuais. Para a construção de uma sociedade mais justa e igualitária, é imprescindível que os trabalhadores tenham seu valor reconhecido em todos os setores sociais.

\section{PANORAMA DA EDUCAÇÃO PROFISSIONAL E TECNOLÓGICA NO BRASIL}

Com relação às origens da Educação Profissional no Brasil, a maioria das sínteses cronológicas inicia-se a partir da chegada dos portugueses e do modelo jesuítico de instrução. Ou seja, o modo de vida indígena, que inclui suas formas de educação, não é levado em conta. Cordão e Moraes (2017, p.18), no entanto, destacam a concepção de educação das nações indígenas do Brasil original pré-cabralino: "Quanto à educação em geral e à educação profíssional em particular, temos convicção de que os processos educacionais indígenas tinham relação mais íntima e direta com a vida cotidiana e com a socialização das pessoas". O trabalho era integrado a outras ações, tais como brincar, pescar, caçar, cozinhar e produzir artefatos.

Cordão e Moraes (2017) afirmam que desde a chegada dos portugueses até grande parte do século XX, a educação profissional foi sempre destinada aos mais pobres. A própria Constituição de 1937 define que "[o] ensino pré-vocacional profissional destinado às classes menos favorecidas é, em matéria de educação, o primeiro dever de Estado" (BRASIL, 1937, art. 129). Os liceus de artes e ofícios, criados a partir de 1850 , no entanto, foram além de seu papel inicialmente assistencialista e tiveram grande influência no desenvolvimento socioeconômico brasileiro. O Liceu de Artes e Ofícios de São Paulo, por exemplo, criado em 1873, tornou-se referência como "escola de qualidade no ensino técnico profissionalizante e na formação geral" (CORDÃO; MORAES, 2017, p. 102) e as primeiras escolas-oficina destinadas à formação profissional de ferroviários "desempenharam papel importante na história da educação profissional brasileira” (CORDÃO; MORAES, 2017, p. 103).

Pensando na história educacional mundial, Enguita (1989, p. 119) faz uma reflexão interessante, que pode ser estendida ao contexto brasileiro no que se refere à Educação Profissional e Tecnológica:

Cabe ainda perguntar-se em que medida não eram os trabalhadores e o movimento operário os primeiros interessados na escolarização universal, em que medida não foi a escola uma conquista operária e popular que as classes dominantes teriam tentado depois e ainda tentariam adulterar com mais ou menos êxito. Infelizmente, a historiografia existente é obra, em sua maior parte, de autores que identificam, no fundamental, a escola com o progresso social, o que provavelmente lhes levou

Laborare. Ano IV, Número 6, Jan-Jun/2021, pp. 142-151. ISSN 2595-847X. https://revistalaborare.org/ DOI: https://doi.org/10.33637/2595-847x.2021-69 
não apenas a uma interpretação enviesada, mas também a uma seleção igualmente enviesada dos dados históricos. Assim, o que normalmente sabemos ou lemos do movimento operário diante da educação é que sempre pediu mais escolas, maior acesso às escolas existentes, etc. Entretanto, há informação suficiente para levar a pensar que, antes da identificação da classe operária com a escola como instrumento de melhoria social, houve um amplo movimento de auto-instrução.

A história oficial da Rede Federal de Educação Profissional, Científica e Tecnológica teve seu início quando Nilo Peçanha, em 1909, criou dezenove escolas de aprendizes artífices. Outro passo importante foi dado com o decreto n. ${ }^{\circ} 5.241$ (BRASIL, 1927), que definiu a obrigatoriedade do ensino profissional nas escolas primárias subvencionadas ou mantidas pela União. Esse fato, segundo Cordão e Moraes (2017, p. 41), denota que "[a] perspectiva já estava se alterando de uma visão assistencialista para uma visão desenvolvimentista". A Constituição de 1988, por sua vez, prevê a formação profissional como parte constituinte do conceito de educação, distanciandose, de maneira definitiva, da sua origem assistencialista:

A educação, direito de todos e dever do Estado e da família, será promovida e incentivada com a colaboração da sociedade, visando ao pleno desenvolvimento da pessoa, seu preparo para o exercício da cidadania e sua qualificação para o trabalho. (BRASIL, 1988, art. 205, grifo nosso).

Legalmente, em nosso país, o ensino integrado se enquadra como uma das formas de oferta da Educação Profissional Técnica de Nível Médio (EPTNM), sendo, de acordo com as Diretrizes Curriculares Nacionais Gerais da Educação Básica, "a melhor ferramenta que a instituição educacional ofertante de cursos técnicos de nível médio pode colocar à disposição dos trabalhadores para enfrentar os desafios cada vez mais complexos do dia a dia de sua vida profissional e social" (BRASIL, 2013, p. 212). A EPTNM, por sua vez, se enquadra como um dos cursos da Educação Profissional e Tecnológica (EPT). Para se compreender o que fundamenta a EPT, faz-se necessário olhar atentamente para os conceitos de técnica e de tecnologia. Ao longo desse olhar, perceber-se-á que, sob a ótica da EPT, tais categorias se distanciam do que é compreendido pelo senso comum.

\section{CONCEITOS-CHAVE DA EDUCAÇÃO PROFISSIONAL E TECNOLÓGICA}

Nos estudos referentes à EPT, a técnica é entendida como característica exclusiva das ações humanas: Vieira Pinto (2005) explica que nas ações dos animais irracionais não há técnica, apenas atos inconscientes predeterminados na codificação genética. $\mathrm{O}$

Laborare. Ano IV, Número 6, Jan-Jun/2021, pp. 142-151. ISSN 2595-847X. https://revistalaborare.org/ DOI: https://doi.org/10.33637/2595-847x.2021-69 
homem difere dos outros animais, portanto, por desempenhar atividades técnicas, pois conscientemente intervém em sua realidade.

Gruber, Allain e Wollinger (2019, p. 125) partem de Vieira Pinto (2005) para definir que a "[t]écnica é uma intervenção humana e qualificada no mundo para produzir a sua existência". Entretanto, Vieira Pinto (2005) explica que, atualmente, existe uma tendência a se considerar a técnica um substantivo, um "ser" com existência própria que pode dominar o homem. Tal discurso, inclusive, afirma que a técnica desumaniza o homem, desconsiderando que a própria nomenclatura das eras pré-históricas remete ao uso dos instrumentos em suas divisões: Era da Pedra Lascada, Era da Pedra Polida, entre outras. Foram as técnicas de uso do fogo, da agricultura, de armas para caça, dentre tantas outras, que propiciaram o processo de humanização. Considerar a técnica como 'inimiga' do homem é historicamente incoerente e serve a propósitos que nem sempre são percebidos:

A substantivação da técnica destina-se a realizar, de má-fé, a adjetivação do homem. Para os efeitos intentados pelos pensadores atrelados aos interesses dos grupos sociais poderosos, convém, mediante a antropomorfização da técnica, fazer passar para segundo plano o papel real desempenhado pelos homens, na verdade as massas trabalhadoras, na construção da história. (VIEIRA PINTO, 2005, p. 180).

A técnica não pode se posicionar acima do homem, dominando-o, simplesmente porque é o próprio homem quem cria a técnica, já que a "produção da existência refere-se tanto às suas condições materiais de vida de ser humano, quanto à constituição de seu ser social, cultural, identitário, entre outras dimensões envolvidas no Trabalho" (GRUBER; ALLAIN; WOLLINGER, 2019, p. 125). Reconhecemos, porém, que ao longo da história "os interesses das classes dominantes converteram-se no elemento propulsor da produção" (ENGELS, 1999, p. 27) e que ao longo da história recente o homem tem se distanciado dos métodos técnicos que produzem a sua existência, destinado a cumprir, por vezes, um papel isolado do todo em diversas linhas de montagem industriais. Tal fato, no entanto, não se deve ao 'lado perverso da técnica', mas sim às estruturas de nossa sociedade. Vieira Pinto (2005, p. 168) explica o propósito das ações dos detentores do instrumental e dos locais de trabalho:

Coagem a consciência do trabalhador a não se entender além do seu campo direto de existência, e não reclamar senão contra a contínua subjugação pela técnica, fazendo assim recair sobre esta o rancor que deveria ser dirigido contra a estrutura geral do trabalho e a classe nobre que dele retira todos os proveitos.

Laborare. Ano IV, Número 6, Jan-Jun/2021, pp. 142-151. ISSN 2595-847X. https://revistalaborare.org/ DOl: https://doi.org/10.33637/2595-847x.2021-69 
A técnica entendida enquanto um 'ser' com existência própria acaba se tornando um mecanismo para esconder as injustiças sociais (VIEIRA PINTO, 2005). Também existe o discurso oposto, igualmente equivocado, de que a técnica é a salvação de todos os males. Ambos os discursos, como dito anteriormente, desconsideram o papel fundamental do homem e das circunstâncias históricas. Vieira Pinto (2005) explica que a expressão 'era tecnológica' refere-se a toda e qualquer época da história, tendo as técnicas de agricultura, domesticação de animais e produção de utensílios de barro o mesmo grau de transcendência que a introdução de novas fontes de energia, tais como as obtidas das reações nucleares. Cabe aqui um importante esclarecimento sobre o sentido do termo tecnologia dentro da EPT:

Partiremos do pressuposto básico de que a Educação Profissional se identifica pela formação para o Trabalho. Este, por sua vez, pode ser definido segundo as contribuições do filósofo brasileiro Álvaro Vieira Pinto (2005) (leitor, entre outros, de Marx), como o exercício social da técnica. Um dos sentidos privilegiados da Tecnologia, na obra do autor, não é o de produto das técnicas, mas sim da tecno-logia como estudo ou ciência da Técnica, o que também dá sentido ao que se chama de Educação Tecnológica. (GRUBER; ALLAIN; WOLLINGER, 2019, p. 124).

Percebe-se, por meio desta citação, que na concepção da EPT o entendimento do que se configura como tecnologia é diferente do seu uso popular enquanto sinônimo de objeto ou produto fruto de técnicas de montagem eletrônicas, tais como computador, Sistema de Posicionamento Global (GPS), celular, entre outros. Em seu sentido epistemológico, a tecnologia consiste na ciência da técnica, cujo foco é o processo de intervenção, diferentemente das ciências tradicionais, que "costumam ter como objeto um conhecimento 'científico', marcadamente teórico, explicativo, verbal ou discursivo" (GRUBER; ALLAIN; WOLLINGER, 2019, p. 125). Já a ciência da técnica - a tecnologia - busca inventar, resolver e intervir. Confirmando essa constatação, Barato (2013, p. 248) afirma que "o saber da técnica, quando inteiramente desenvolvido, dispensa verbalização".

A compreensão de que os saberes da tecnologia possuem uma natureza diferente dos saberes das ciências tradicionais permite superar a dicotomia, tão presente em nosso sistema educacional, entre atividade manual/corporal e atividade intelectual $/ \mathrm{mental}$ : "via de regra, o conhecimento técnico é associado à 'prática' e à Teoria se associa a Ciência.

Com isso, tende-se a esvaziar a Técnica de saber, o qual fica restrito ao âmbito da Teoria" (GRUBER; ALLAIN; WOLLINGER, 2019, p. 125).

Laborare. Ano IV, Número 6, Jan-Jun/2021, pp. 142-151. ISSN 2595-847X. https://revistalaborare.org/ DOI: https://doi.org/10.33637/2595-847x.2021-69 
Os saberes do trabalho que não são necessariamente verbalizados tendem a ser, em nossa sociedade, desvalorizados. Tal comportamento, fruto de nossa história escravocrata, nos deixa 'cegos' para toda a riqueza de conhecimentos presentes em atividades tidas como 'práticas'. Barato (2013) alerta que a divisão do saber nas categorias de teoria e prática alimenta preconceitos e desqualifica os trabalhadores. Engels ([1876] 1999, p. 24) já confirmava, em seu tempo, a incoerência dessa divisão: "ideia absurda e antinatural da antítese entre o espírito e a matéria, o homem e a natureza, a alma e o corpo". De acordo com Gruber, Allain e Wollinger (2019, p. 125), "a Técnica é um composto de fazeres e saberes e estes fazeres em si mesmos já configuram formas de saber, ou 'fazer-saber"'. Percebe-se, assim, toda a complexidade requerida pelos saberes do fazer.

Segundo a didática para o ensino técnico, como entendida por Barato (2003, p. 17), devemos considerar o fazer-saber como "uma dimensão epistemológica cuja origem e fundamento é a própria ação, não um pensar que a antecede". $\mathrm{O}$ ato de fazer é compreendido, por si próprio, como um saber. Essa noção recupera as origens da educação profissional, que costumam ser mal interpretadas: "o modelo cujas bases nasceram no chão de oficinas e ateliês, a aprendizagem corporativa, é esquecido ou criticado pelos educadores" (BARATO, 2003, p. 22). Os saberes do fazer exigem criatividade e inteligência, em um contínuo processo de elaboração e re-elaboração do conhecimento, que se distancia, completamente, da noção de técnica como 'ato mecânico'. Barato (2003) defende que os sistemas de ensino se adequem às características do tipo de conhecimento que pretendem promover, dando prioridade à técnica e não à verbalização teórica de seus fundamentos.

Sennet (2013) acredita que o processo de valorização do trabalhador deve partir de um materialismo cultural mais vigoroso: materialismo no sentido de aprender com as coisas, saber apreciar as qualidades de uma vestimenta ou a maneira certa de escaldar um peixe; e cultural no sentido de compreender como as coisas produzidas geram prazer e valores. Ao se compreender os saberes e habilidades que são demandados do trabalhador, as suas ações poderão ser medidas em uma escala de competência justa e real, sem hierarquização. Vieira Pinto (2005, p. 103) cita um exemplo elucidativo nesse sentido:

A caneta esferográfica com que estamos escrevendo representa por si uma máquina e o produto da operação de uma série de outros mecanismos. Mas ignoramos de todo modo como é feita e que operações exige para chegar a ser um objeto de uso. Neste sentido é que falamos de distanciamento do homem em relação à máquina. Deve ser entendido este conceito em sentido dialético, na contradição contida na condição de afastamento. Por um lado, o homem distanciase das máquinas, a ponto de ignorá-las, mas só se pode dar ao luxo desse

Laborare. Ano IV, Número 6, Jan-Jun/2021, pp. 142-151. ISSN 2595-847X. https://revistalaborare.org/ DOI: https://doi.org/10.33637/2595-847x.2021-69 
comportamento exatamente porque cada vez está mais próximo delas, mais envolvido por elas, sob a espécie de consumo dos bens que produzem.

A tecnologia explica as técnicas usadas para a produção dos artefatos e, por meio da compreensão delas, valorizamos sua invenção e produção. No passado, como indica a citação, era necessário o conhecimento das técnicas pelo fato de não estarem disponíveis como bens de consumo. Atualmente, pode-se ignorar esse conhecimento, porém sob o risco de nos distanciarmos de nossa essência, que é a de produtores de nossa existência. Tal distanciamento pode, ainda, fazer com que consideremos inédita uma técnica em vigor, mesmo ela já sendo antiga. Vieira Pinto (2005) afirma que a ciência da informação, cognominada informática, consiste na forma original como repete um velho procedimento que sempre os homens executaram para viverem em comunidade, a saber, comunicarem-se uns com os outros: as máquinas recebem dados, os processam e depois fornecem ordens de ação ou transmitem informações. Pode parecer óbvio ressaltar, mas essas ações são realizadas a partir de instruções humanas e não indicam, como muitos afirmam, que as máquinas pensam sozinhas e, menos ainda, que irão nos subjugar:

Ao nos referirmos a máquinas que procedem a escolhas, tomam iniciativas e fazem outras imitações do comportamento inteligente, estamos relaxando o rigor da linguagem e esquecendo serem essas façanhas produto da capacidade de deliberada transferência de poderes, em virtude da qual o cérebro humano, único órgão capaz de elaborar projetos, elabora um projeto especial, o de uma máquina elaboradora de projetos". (VIEIRA PINTO, 2005, p. 95).

Existe um natural fascínio e admiração por tantos progressos técnicos que nos cercam ou que estão em fase de desenvolvimento, principalmente na área da informática. Entretanto, pelo interesse dos setores dominantes da sociedade em manter o status quo, há uma tendência em se considerar as invenções como entidades em si, a referida substantivação da técnica (VIEIRA PINTO, 2005). Retomar o conhecimento acumulado das técnicas que nos cercam é importante no sentido de colocar o homem como centro do processo criativo de produção. É reconhecer que dele advém qualquer possibilidade de mudança e que as condições atuais de exploração do trabalhador não são inerentes ao progresso tecnológico: "esta situação, que presentemente configura a tragédia do trabalhador submisso à máquina, na verdade ao proprietário dela, sendo histórica, por isso mesmo nada tem de definitivo" (VIEIRA PINTO, 2005, p. 131). Ao longo da história da humanidade, várias organizações sociais, consideradas imutáveis, tiveram seu declínio: o colonialismo, a escravidão, o patriarcado, dentre outras. Assim, também a condição de submissão dos trabalhadores aos proprietários dos meios de produção pode ser modificada.

Laborare. Ano IV, Número 6, Jan-Jun/2021, pp. 142-151. ISSN 2595-847X. https://revistalaborare.org/ DOI: https://doi.org/10.33637/2595-847x.2021-69 
A discussão de aspectos referentes ao nosso atual modelo econômico e social tende a fazer nascer propostas que vislumbrem uma mudança. O primeiro passo é refletir criticamente sobre os discursos que, como vimos, culpabilizam a técnica e desvalorizam o trabalhador. Segundo Vieira Pinto (2005, p. 226), a consciência crítica é aquela que "toma consciência de seus determinantes no processo histórico da realidade, sempre, porém apreendendo o processo em totalidade e não considerando determinantes os fatores correspondentes aos interesses individuais privados".

\section{CONCLUSÃO}

A relação entre trabalho e Educação Profissional precisa ser cada vez mais abordada no sentido de se reconhecer a importância da formação de trabalhadores como agentes de transformação social. Com este artigo, pretendeu-se abordar os conceitos de técnica e de tecnologia no âmbito da EPT, ambos buscando valorizar os saberes provenientes de profissões que privilegiam o processo de intervenção em detrimento da verbalização. A complexidade requerida pelos saberes do fazer precisa ser reconhecida em todas as esferas de nossa sociedade, em especial pelas instituições de Educação Profissional.

\section{REFERÊNCIAS BIBLIOGRÁFICAS}

BARATO, Jarbas Novelino. Educação profissional: saberes do ócio ou saberes do trabalho? São Paulo: Senac, 2003. 3,2013.

O saber no salão de beleza. Trabalho \& Educação, Belo Horizonte, v. 22, n.

Fazer bem feito: valores em educação profissional e tecnológica. Brasília: UNESCO, 2015.

BRASIL. Decreto n. ${ }^{0}$ 5.241, de 22 de agosto de 1927. Cria o ensino profissional obrigatório nas escolas primárias subvencionadas ou mantidas pela União, bem como no Colégio Pedro II e estabelecimentos a este equiparado e dão outras providencias. Diário Oficial da República Federativa do Brasil, Poder Executivo, Rio de Janeiro, Seção 1. 26 ago. 1927. Nacional, 1937.

Constituição da República Federativa do Brasil. Brasília: Congresso . Constituição da República Federativa do Brasil. Brasília: Congresso Nacional, 1988.

Laborare. Ano IV, Número 6, Jan-Jun/2021, pp. 142-151. ISSN 2595-847X. https://revistalaborare.org/ DOl: https://doi.org/10.33637/2595-847x.2021-69 
Ministério da Educação. Secretaria de Educação Básica. Secretaria de Educação Continuada, Alfabetização, Diversidade e Inclusão. Conselho Nacional da Educação. Diretrizes Curriculares Nacionais Gerais da Educação Básica. Brasília: MEC, 2013.

CORDÃO, Francisco Aparecido; MORAES, Francisco de. Educação profissional no Brasil: síntese histórica e perspectivas. São Paulo: Senac, 2017.

ENGELS, Friedrich. Sobre o papel do trabalho na transformação do macaco em homem (1876). Ed. Ridendo Castigat Mores, 1999.

ENGUITA, Mariano Fernández. A face oculta da escola. Tradução de Tomaz Tadeu da Silva. Porto Alegre: Artes Médicas, 1989.

GRUBER, Crislaine; ALLAIN, Olivier; WOLLINGER, Paulo. Contribuições da Didática Profissional para a Educação Profissional Brasileira. In: GRUBER, Crislaine; ALLAIN, Olivier; WOLLINGER, Paulo (Orgs.). Didática profissional: princípios e referências para a Educação Profissional. Florianópolis: Publicações do IFSC, 2019.

SENNETT, Richard. O Artífice. $4^{\text {a }}$ edição. Rio de Janeiro: Record, 2013.

VIEIRA PINTO, Álvaro. O conceito de tecnologia (Volume 1). Rio de Janeiro: Contraponto, 2005.

Recebido: 08/12/2020

Revisado: 23/01/2021

Aprovado: 26/01/2021 